\title{
LINFOMA RENAL: ESPECTRO DE IMAGENS NA TOMOGRAFIA COMPUTADORIZADA*
}

\author{
Carol Pontes de Miranda Maranhão ${ }^{1}$, Tufik Bauab Jr. ${ }^{2}$
}

Resumo 0 acometimento renal no linfoma é raro, uma vez que o rim não possui tecido linfóide. 0 envolvimento secundário é mais freqüente, ocorrendo em até um terço das autópsias dos portadores de linfoma. Alguns autores acreditam que esta seja a única forma de acometimento renal, questionando a existência do linfoma primário. $O$ linfoma renal representaria metástases hematogênicas ou invasão direta do tumor ocorrendo no espaço perirrenal. A partir destes tipos de envolvimento decorrem as formas de apresentação do linfoma renal: múltiplos nódulos, massa solitária, invasão renal por doença retroperitoneal contígua, doença perirrenal e infiltração difusa. Neste trabalho são discutidas e apresentadas imagens destas diferentes formas de acometimento.

Unitermos: Rim; Linfoma; Tomografia computadorizada.

Abstract Renal lymphoma: spectrum of computed tomography findings. Isolated renal lymphoma is rare due to the absence of lymphoid tissue in kidneys. Secondary involvement occurs more frequently and is reported in up to $1 / 3$ of the autopsies of patients who died from lymphoma. Some authors believe this is actually the only existing form of renal lymphoma. The involvement of the kidney by lymphoma would occur through hematogenic metastasis or direct tumor invasion of the perirenal space. These different types of involvement determine the several forms of renal lymphoma presentation: multiple nodules, solitary mass, renal invasion from contiguous retroperitoneal disease, perirenal disease and diffuse infiltration. In this study the imaging findings features of the different forms of involvement are presented and discussed.

Key words: Kidney; Lymphoma; Computed tomography.

\section{INTRODUÇÃO}

Os rins não têm tecido linfóide nativo. Por esse motivo, o linfoma primário renal é uma entidade rara, inclusive sendo questionada a sua ocorrência. A incidência do linfoma renal primário continua desconhecida e não é claro se esta lesão pode ser diagnosticada pré-operatoriamente utilizando-se estudos de imagem $^{(\mathbf{1})}$.

Já o envolvimento secundário do rim é freqüiente, ocorrendo em até um terço das autópsias dos portadores de linfoma ${ }^{(2)}$. Alguns autores acreditam que esta seja a única forma de acometimento renal, questionando a existência do linfoma primá-

* Trabalho realizado no Hospital de Base da Faculdade de Medicina de São José do Rio Preto (Famerp), São José do Rio Preto, SP.

1. Médica Residente do Departamento de Imagem do Hospital de Base da Famerp, Membro Titular do Colégio Brasileiro de Radiologia e Diagnóstico por Imagem (CBR).

2. Doutor em Medicina pela Faculdade de Medicina da Universidade de São Paulo (FMUSP), Professor Adjunto Doutor e Chefe da Residência em Imagem da Famerp.

Endereço para correspondência: Prof. Dr. Tufik Bauab Jr. Rua San Francisco, 555. São José do Rio Preto, SP, 15093-030. E-mail: tbauab@riopreto.com.br

Recebido para publicação em 22/10/2003. Aceito, após revisão, em 27/1/2004. rio $^{(3)}$. O linfoma renal representaria metástases hematogênicas ou invasão direta do tumor crescendo no espaço perirrenal.

As metástases hematogênicas geralmente produzem nódulos múltiplos e bilaterais. Uma vez que o linfoma cresce por infiltração, nem sempre é nítida a delimitação entre os depósitos linfomatosos e o parênquima normal adjacente. O rim começa a aumentar e inicialmente é mantido o aspecto reniforme. Mais tardiamente, as massas linfomatosas se tornam tão grandes que o aspecto reniforme é perdido e os rins mostram contornos lobulados.

A invasão direta a partir dos espaços perirrenais pode ocorrer através do seio renal (quando a massa linfomatosa é medial ao rim), sendo chamada de disseminação transinusal, assim como através da cápsula renal (quando a massa linfomatosa é lateral ao rim), sendo chamada de disseminação transcapsular.

\section{QUADRO CLÍNICO}

Mesmo tendo aspectos clínicos, patológicos e prognóstico diferentes, todas as formas de linfoma têm padrões semelhantes de envolvimento renal. A forma nãoHodgkin da doença é a que mais comumente envolve o rim.

Também é mais provável que o rim esteja envolvido nas formas difusas do que nas formas nodulares de linfoma ${ }^{(4)}$. No quadro clínico do linfoma, os sintomas relacionados ao envolvimento do trato urinário são pobres, sendo rara a insuficiência renal; os nódulos no parênquima renal podem produzir dor ou sensibilidade à palpação do flanco, massa palpável ou hematúria. Se as massas ocuparem o hilo renal, podem levar à hipertensão ou oclusão da veia renal. O envolvimento dos ureteres pode causar uropatia obstrutiva. São freqüentes a proteinúria, cilindrúria, hipercalcemia e elevação da uréia sanguínea.

\section{FORMAS DE APRESENTAÇÃO DO LINFOMA RENAL}

A morfologia macroscópica e, conseqüentemente, a imagem radiográfica dependem do mecanismo do envolvimento renal (hematogênico ou extensão direta), 
do padrão de crescimento intra-renal (intersticial ou expansivo), do tamanho, número e distribuição das lesões, e da presença de extensão além do rim. Inicialmente a detecção radiológica pode ser difícil, uma vez que o linfoma cresce entre os néfrons (que continuam a funcionar) e que a proliferação intersticial preserva a morfologia macroscópica. Com a progressão da lesão, o arcabouço através do qual o tumor se infiltra é destruído, e o crescimento torna-se expansivo e a massa linfomatosa assemelha-se a outras neoplasias renais que crescem por aposição. $\mathrm{O}$ crescimento contínuo e a coalescência dos pequenos focos resultam em envolvimento progressivo do parênquima e, raramente, destruição de todo o rim. Extensão perinéfrica com subseqüente envolvimento vascular e ureteral é comum $^{(5)}$.

O diagnóstico de linfoma renal usualmente não é difícil porque quase sempre sabe-se de antemão que o paciente é portador de linfoma. O linfoma tem várias formas de apresentação. Existe discordância na literatura, sendo citados três ${ }^{(6)}$, quatro ${ }^{(7)}$ ou cinco ${ }^{(4)}$ padrões de apresentação. Ainda que nenhuma correlação específica entre o tipo exato de envolvimento linfomatoso e o padrão de envolvimento renal tenha sido encontrada, e ainda que de alguma maneira estes padrões sejam arbitrariamente definidos, seguiremos a divisão proposta por Urban e Fishman ${ }^{(4)}$ : múltiplos nódulos, massa solitária, invasão renal por doença retroperitoneal contígua, doença perirrenal e infiltração renal difusa.

\section{MÚLTIPLOS NÓDULOS}

O padrão de múltiplos nódulos é o mais comum tipo de envolvimento renal pelo linfoma, sendo encontrado em $61 \%$ dos $\operatorname{casos}^{(2)}$. O acometimento pode ser unilateral, mas tipicamente é bilateral.

As massas não são encapsuladas e podem ter margens irregulares. Dependendo do tamanho e expansão natural dos depósitos individuais, pouco efeito de massa pode ser visto no contorno renal (Figuras 1 e 2). Mesmo que haja envolvimento re-

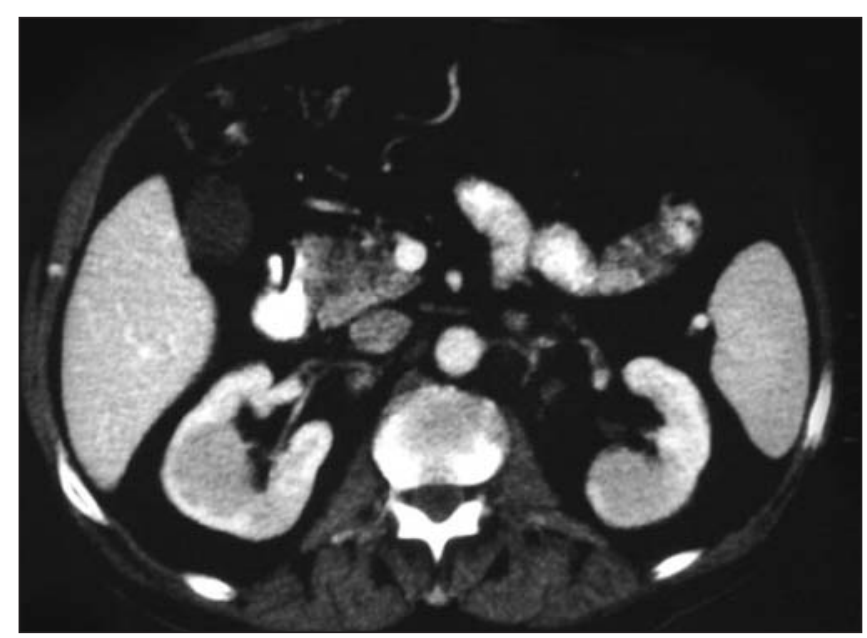

A

Figura 1. Linfoma renal bilateral na forma de massas múltiplas. O aspecto reniforme está mantido, com contornos renais lisos. A maior parte do parênquima está preservada. Podem ser vistos alguns linfonodos aumentados de tamanho.

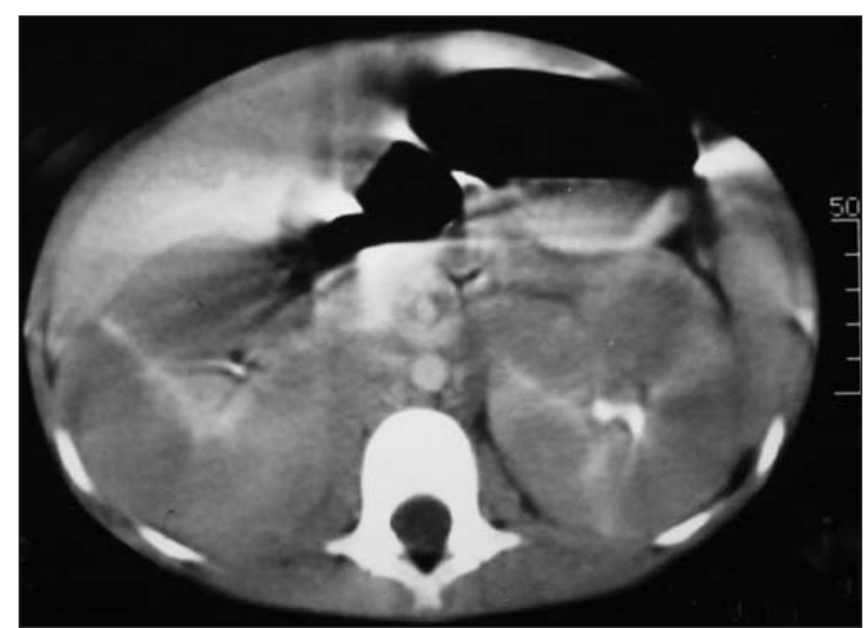

A

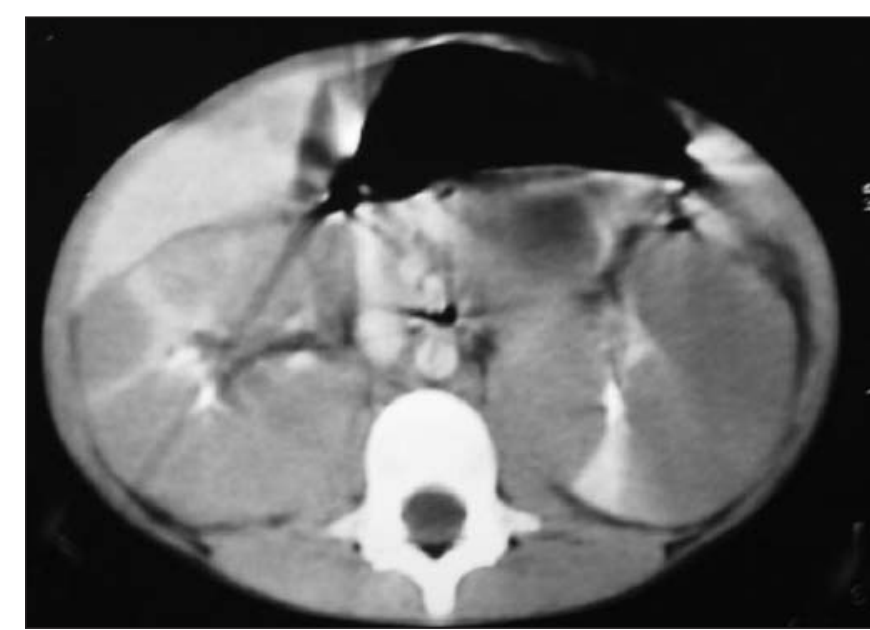

B

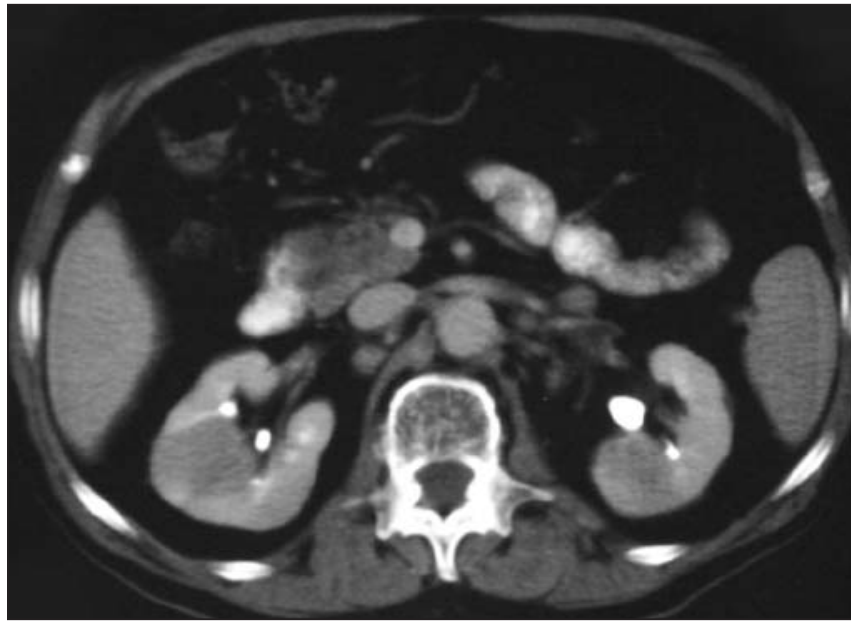

B

Figura 2. Linfoma renal bilateral na forma de múltiplas massas em fase mais avançada. 0 aspecto reniforme está mantido, com contornos renais lisos, mas os rins estão bastante aumentados de tamanho. As massas substituem grande parte do parênquima. 
nal extenso, os achados de imagem podem ser sutis e administração endovenosa do meio de contraste torna-se essencial para o diagnóstico, uma vez que, antes da administração do meio de contraste, a atenuação do tecido linfomatoso é ligeiramente menor que a do parênquima normal (Figura 3A). Raramente o tecido linfomatoso é hiperdenso. O realce pelo meio de contraste é mínimo, sempre menor que o do parênquima normal (Figuras $3 \mathrm{~B}$ e $3 \mathrm{C}$ ) e habitualmente homogêneo ou minimamente heterogêneo ${ }^{(7)}$. As massas típicas medem entre 1 e $3 \mathrm{~cm}$; um aspecto heterogêneo ou cístico raramente é visto e tipicamente é um sinal de necrose tumoral em pacientes submetidos a quimioterapia.

O diagnóstico diferencial de massas renais múltiplas bilaterais inclui metástases, hematopoiese extramedular e doença de von Hippel-Lindau em que o componente sólido seja predominante.

\section{MASSA SOLITÁRIA}

Quando o crescimento de um foco linfomatoso é não-uniforme, excêntrico ou relativamente rápido, o achado será de massa renal isolada, que pode ser confundida com outras neoplasias renais que crescem por expansão, como o carcinoma de células renais ou metástases (Figura 4). As massas linfomatosas são tipicamente hipovasculares e demonstram mínimo realce após administração endovenosa do meio de contraste (Figura 5), o que pode ajudar na diferenciação do linfoma do carcinoma de células renais, que tem um padrão de realce típico. Além disso, a atenuação do linfoma é homogênea, enquanto o carcinoma tende a ser heterogêneo. Também ajuda na diferenciação o fato de que neoplasias primárias (como o carcinoma e o tumor de Wilms) freqüentemente são encapsuladas, enquanto a massa linfomatosa permanece não encapsulada e com margens mal definidas devido ao crescimento do tipo infiltrativo. Apesar disso, freqüentemente é necessária biópsia para diagnóstico definitivo. Massas solitárias têm freqüência de cerca de $14 \%$ e o tamanho pode chegar até a $15 \mathrm{~cm}$ de diâmetro, distorcendo o contorno renal ${ }^{(4,5)}$.

\section{INVASÃO RENAL POR DOENÇA RETROPERITONEAL CONTÍGUA}

Em cerca de $25 \%$ dos portadores de linfoma renal o acometimento ocorre por disseminação a partir de doença retroperitoneal vizinha. Tipicamente estes pacientes têm grande massa retroperitoneal, que pode envolver as artérias e veias e invadir o hilo do rim. As massas linfomatosas mostram, em geral, atenuação homogênea e, mais raramente, discretamente heterogênea ${ }^{(7)}$. Mesmo envolvidos pelo linfoma, os vasos
Figura 3. Linfoma renal bilateral na forma de massas múltiplas em fase mais avançada. Na fase pré-contraste venoso o aspecto reniforme está mantido e os contornos renais são lisos. Os rins estão bastante aumentados de tamanho, mas as massas não são perceptíveis pela isodensidade com o parênquima. Após administração de meio de contraste venoso, tanto na fase nefrográfica como na urográfica é possível notar que as massas substituem grande parte do parênquima.

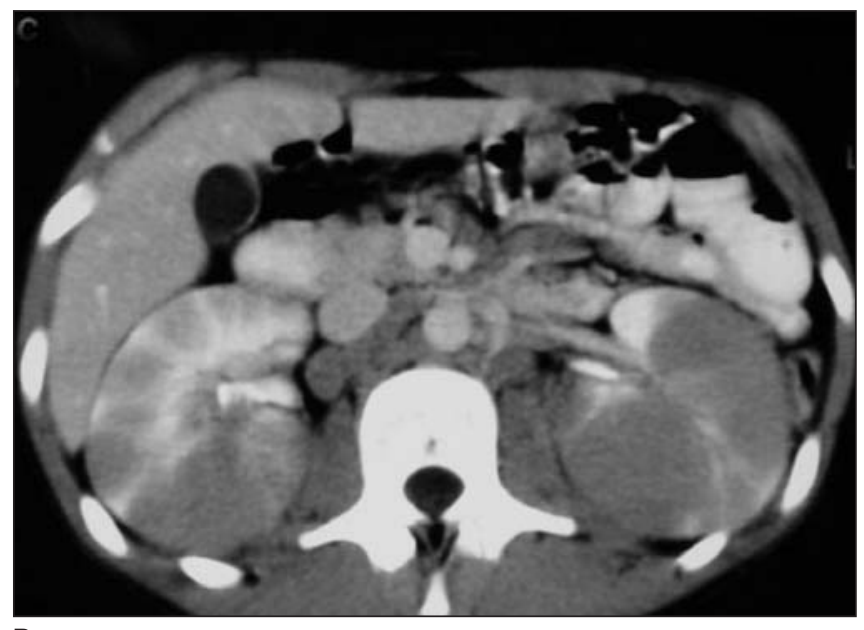

$\mathbf{B}$

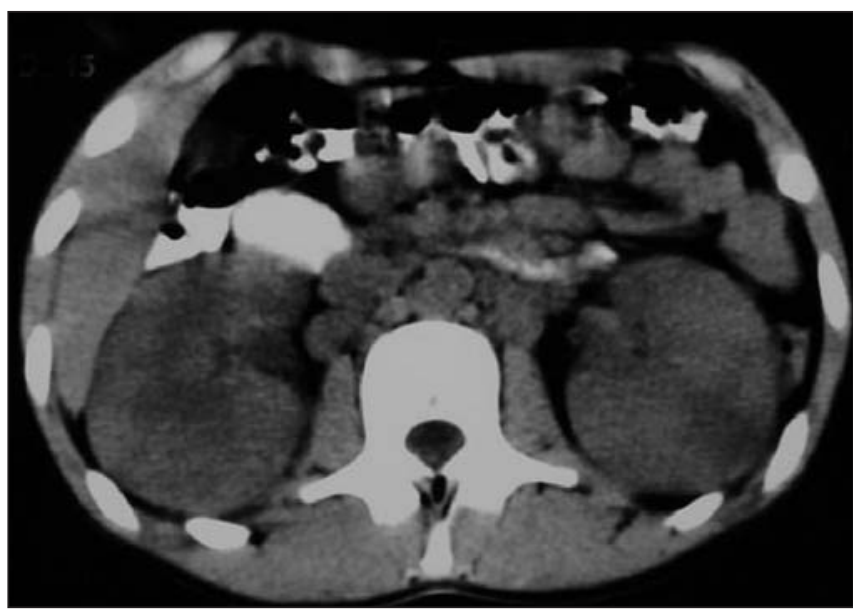

A

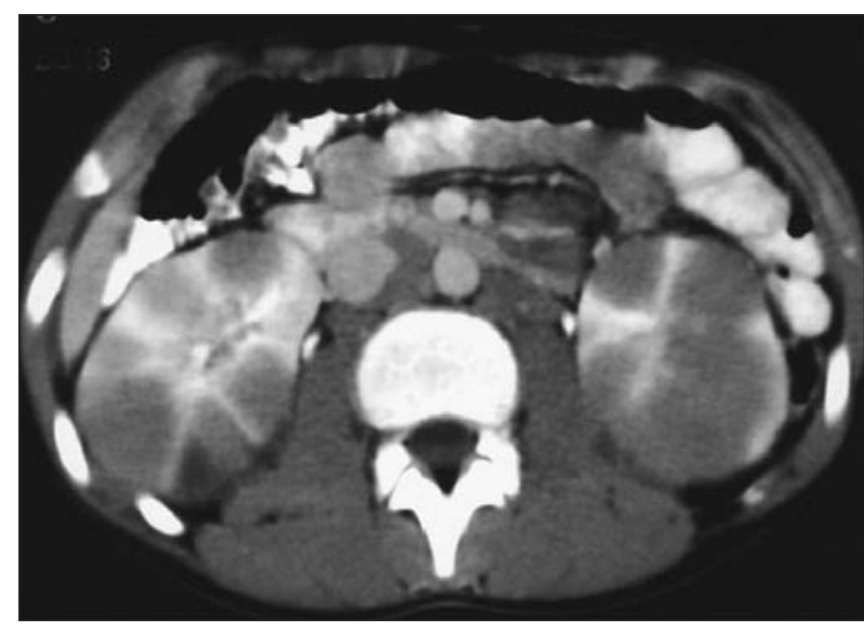

C 


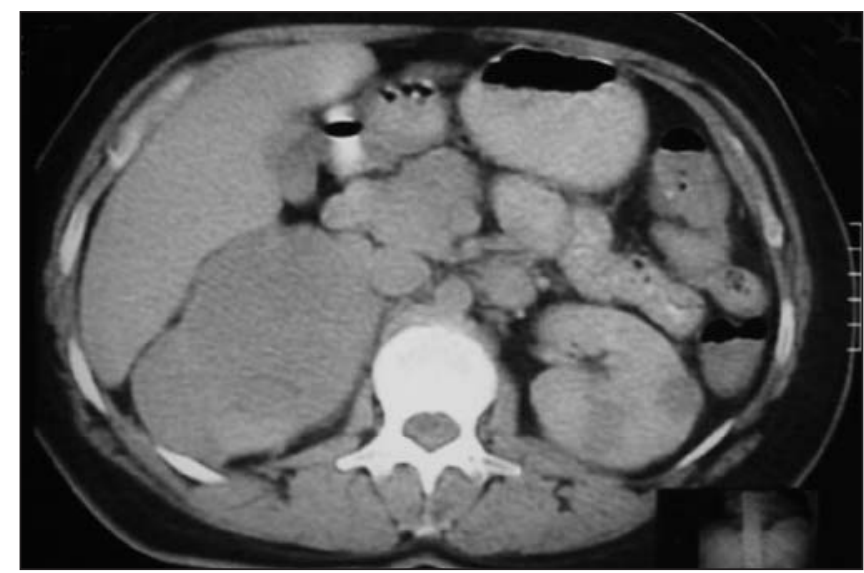

A

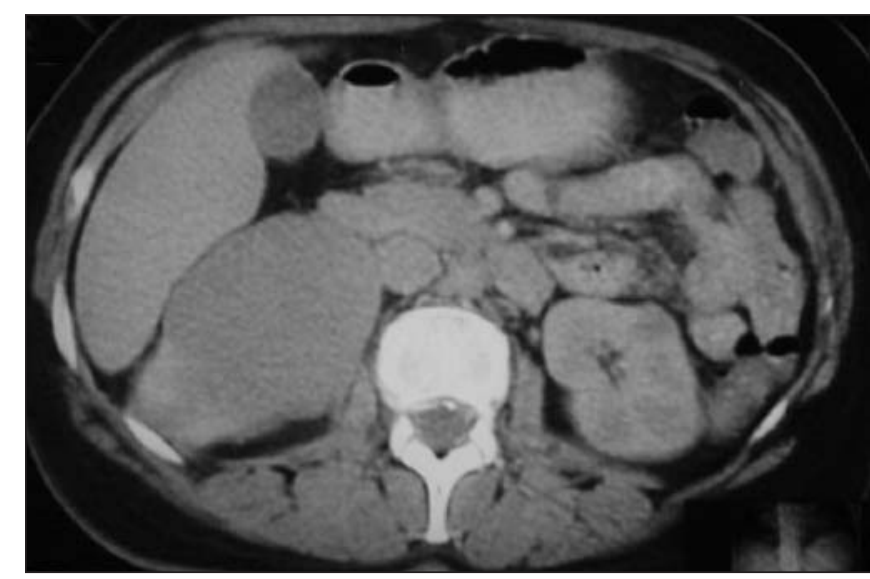

B

Figura 4. Linfoma bilateral com crescimento desigual das massas. Presença de grande massa no rim direito, com predomínio visual que pode ser confundido com massa solitária, caso passem despercebidas as pequenas massas no rim esquerdo.

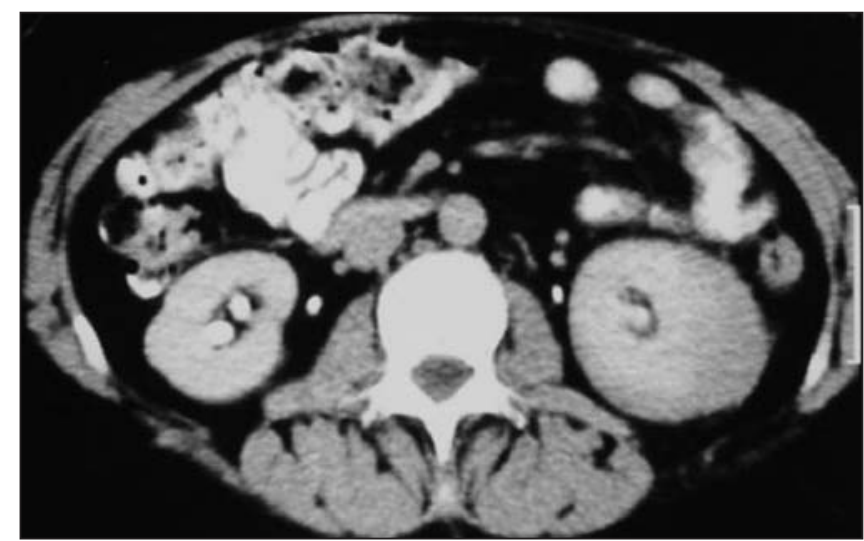

A

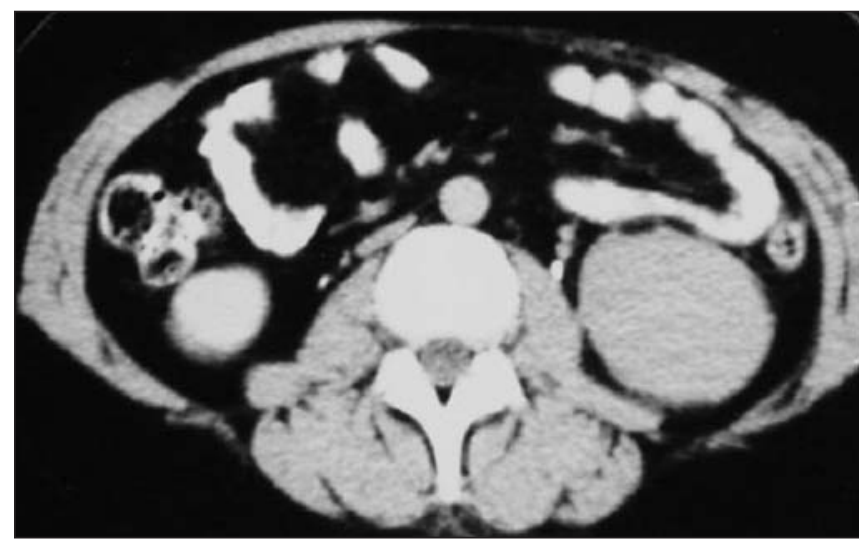

B

Figura 5. Linfoma renal unilateral na forma de massa solitária. A massa é periférica, no pólo inferior do rim esquerdo, mostra baixa captação do meio de contraste, é homogênea e pode ser confundida com outras neoplasias renais.

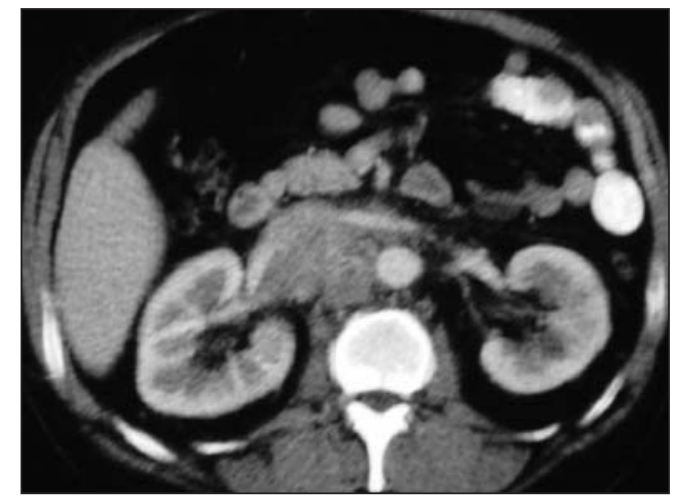

A

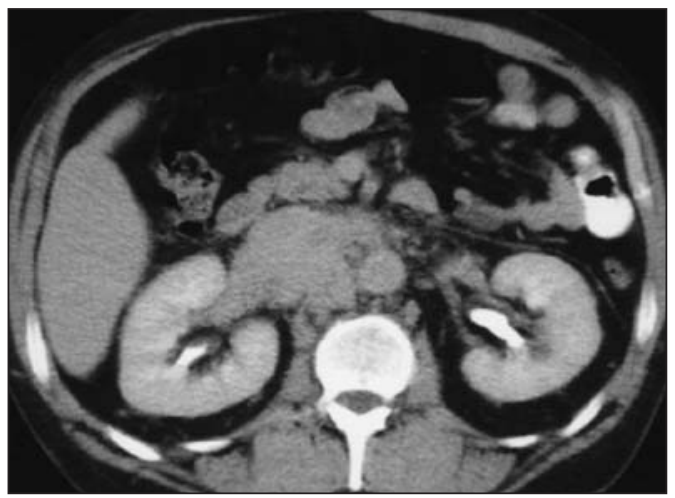

B hilares permanecem pérvios, um achado característico do linfoma (Figuras 6A, 8A e 13A). Já o sistema coletor pode ser obstruído pelo envolvimento contíguo retroperitoneal, com obstrução e conseqüente hidronefrose (Figura 7). A massa linfomatosa pode desviar o rim (Figura 9) ${ }^{(2)}$.

\section{DOENÇA PERIRRENAL}

O linfoma primariamente retroperitoneal pode estender-se para o espaço perirrenal. O envolvimento perirrenal pelo linfoma também pode resultar de extensão direta de disseminação transcapsular de uma
Figura 6. Linfoma retroperitoneal crescendo em direção ao seio renal. Nota-se envolvimento dos vasos hilares renais na fase arterial. Na fase urográfica nota-se invasão inicial do parênquima. doença do parênquima. A doença perirrenal pode ocorrer sem envolvimento notável do parênquima, o que é mais raro ${ }^{(5)}$ Nestes casos, a doença pode envolver completamente o rim, sem compressão do parênquima ou prejudicar a função. Embora infreqüente, este aspecto é praticamente 
Figura 7. Linfoma retroperitoneal crescendo em direção ao seio renal. Aparentemente não há invasão do parênquima, mas a massa linfomatosa provoca obstrução e hidronefrose.

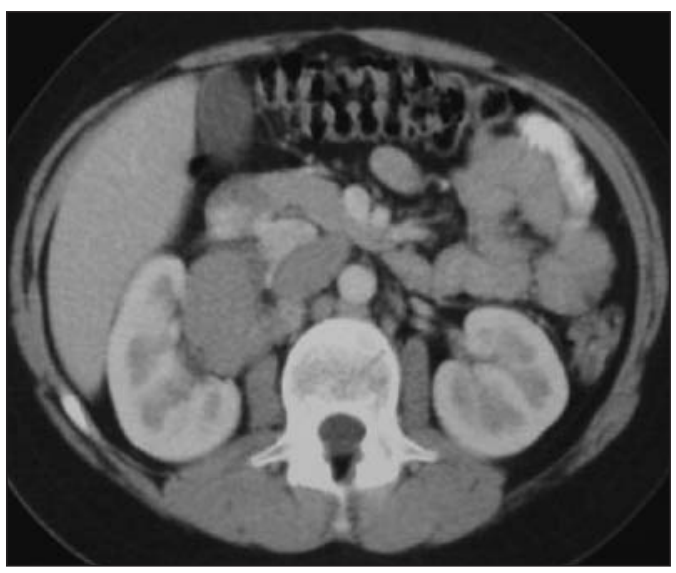

A

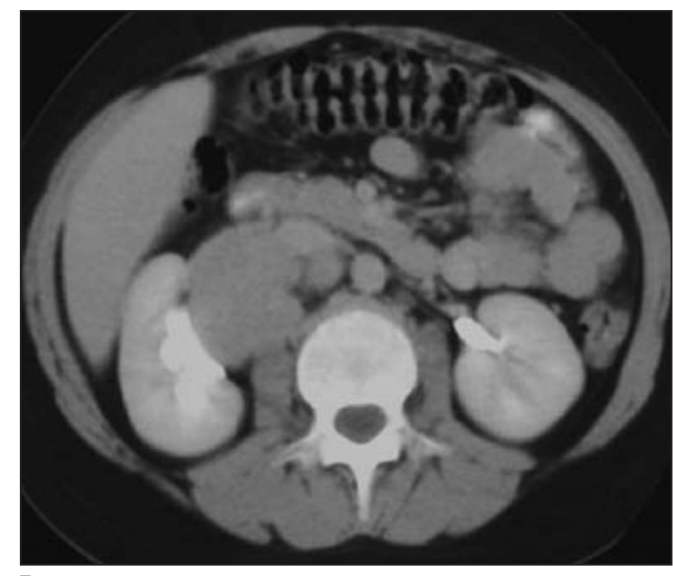

B

Figura 8. Linfoma retroperitoneal crescendo em direção ao seio renal. A extensa massa linfomatosa envolve os vasos hilares e a pelve renal e invade o parênquima.

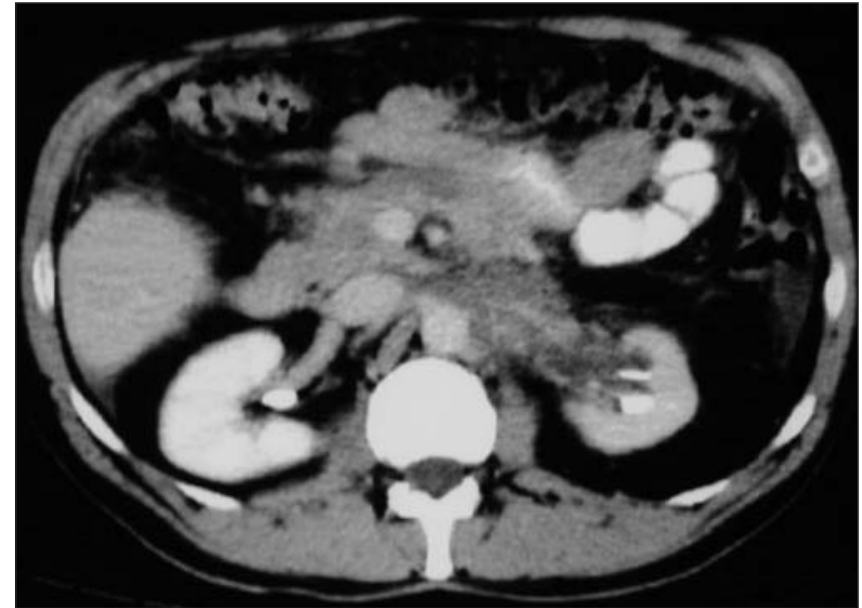

B

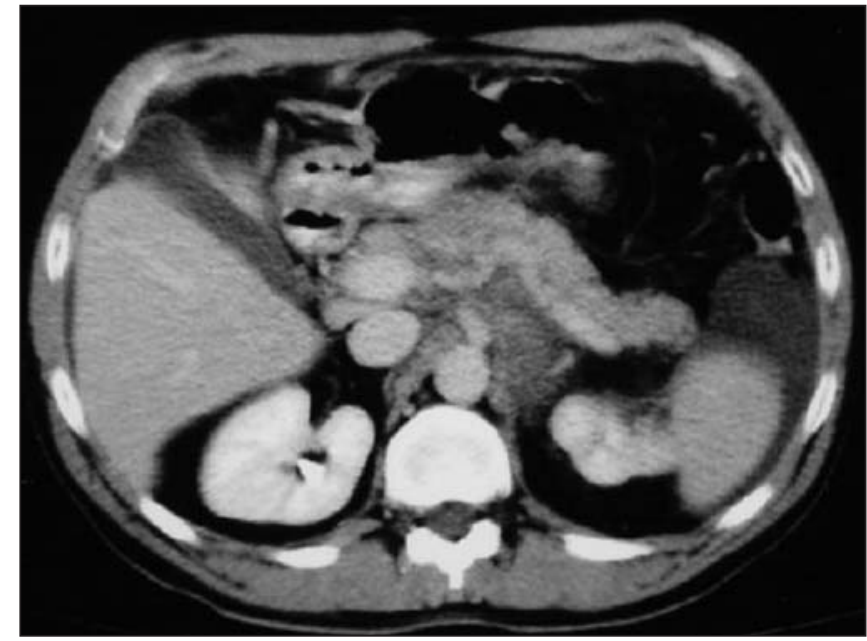

A

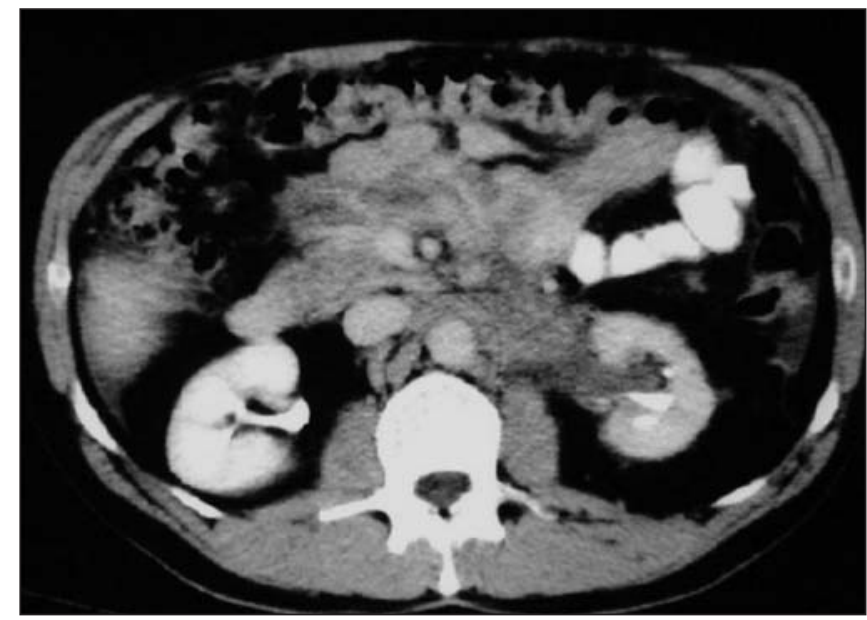

C patognomônico do linfoma renal. O acometimento perirrenal pode apresentar-se como infiltração do seio renal, espessamento da fáscia de Gerota e/ou massas perirrenais (Figuras 10 e 11). A diferenciação entre a lesão perirrenal e o parênqui- ma subjacente pode ser difícil na fase sem contraste: a massa perirrenal pode ser confundida com hematoma subcapsular; na maioria dos casos é indispensável a injeção venosa de meio de contraste para detecção

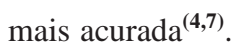

\section{INFILTRAÇÃO DIFUSA}

A proliferação linfomatosa geralmente ocorre no interstício renal, resultando em aumento do tamanho sem distorção dos contornos. Esta forma é quase sempre bi- 

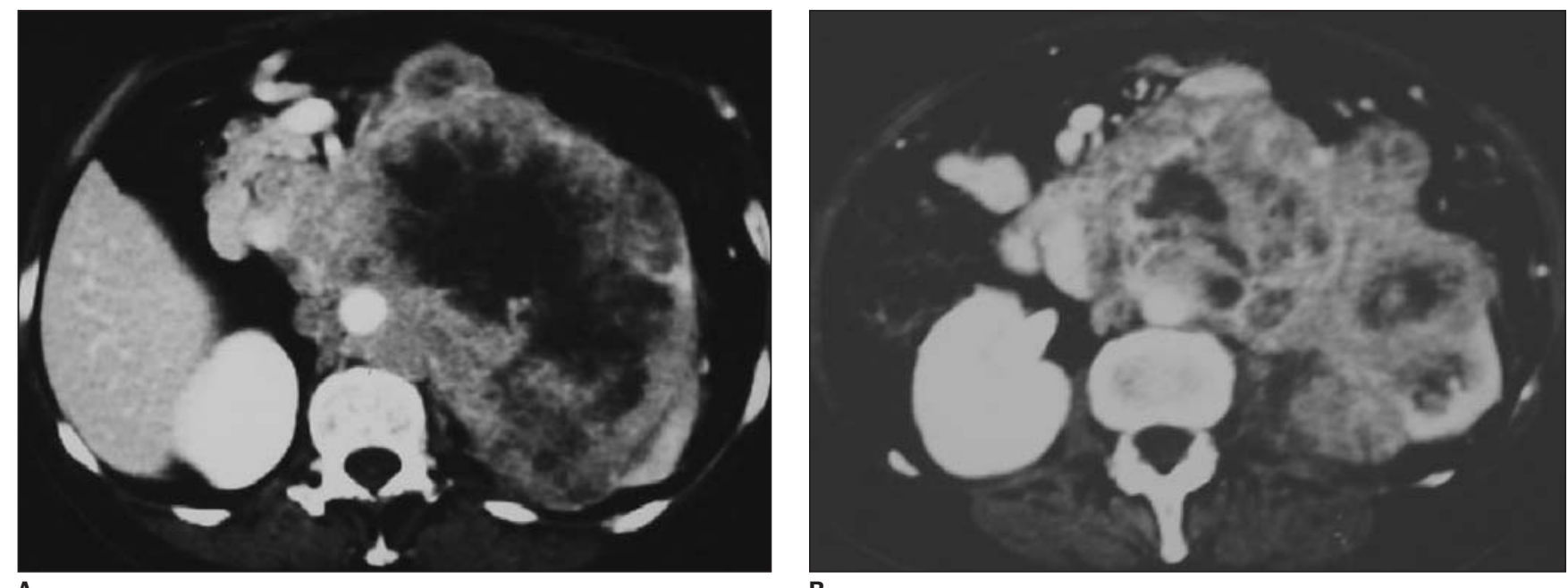

A

B

Figura 9. Linfoma retroperitoneal. A massa retroperitoneal é pequena em relação ao extenso comprometimento renal, que tem praticamente todo o parênquima substituído.
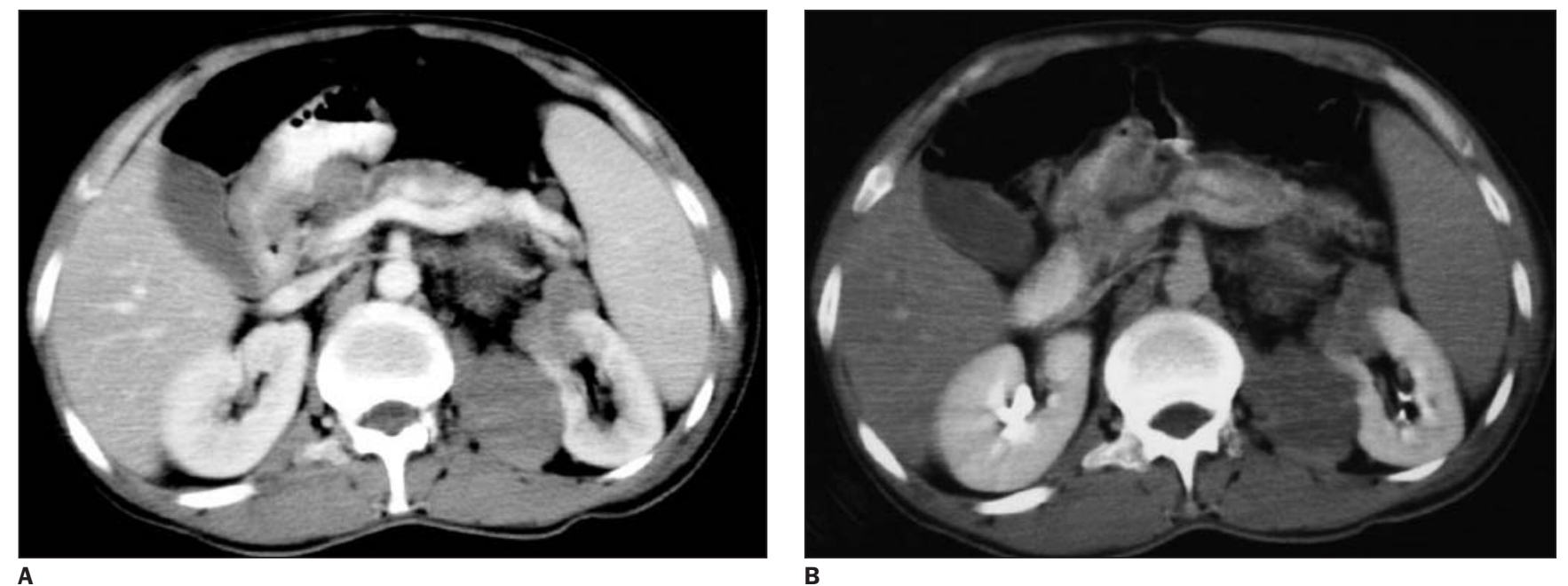

A

Figura 10. Linfoma retroperitoneal crescendo em direção ao seio e ao espaço perirrenal medial, onde é possível notar envolvimento do parênquima em fase inicial.

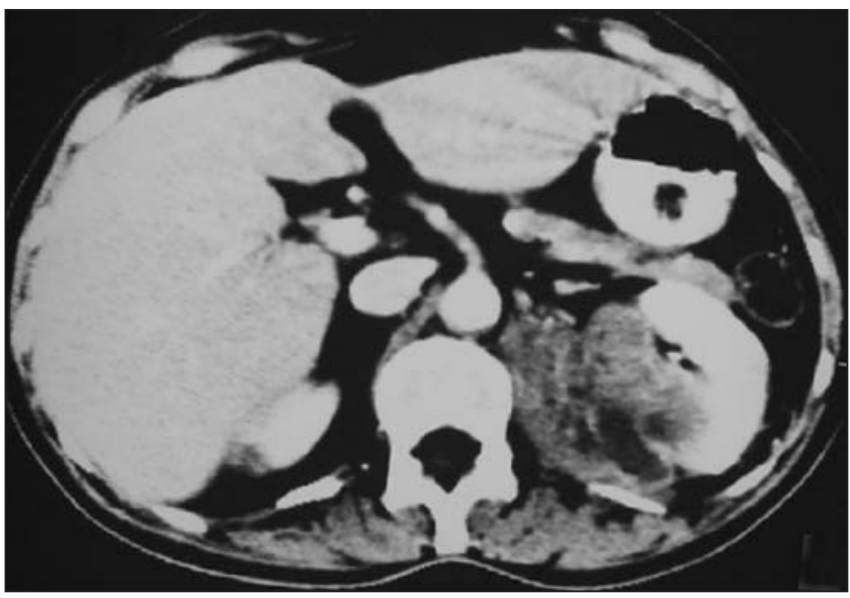

A

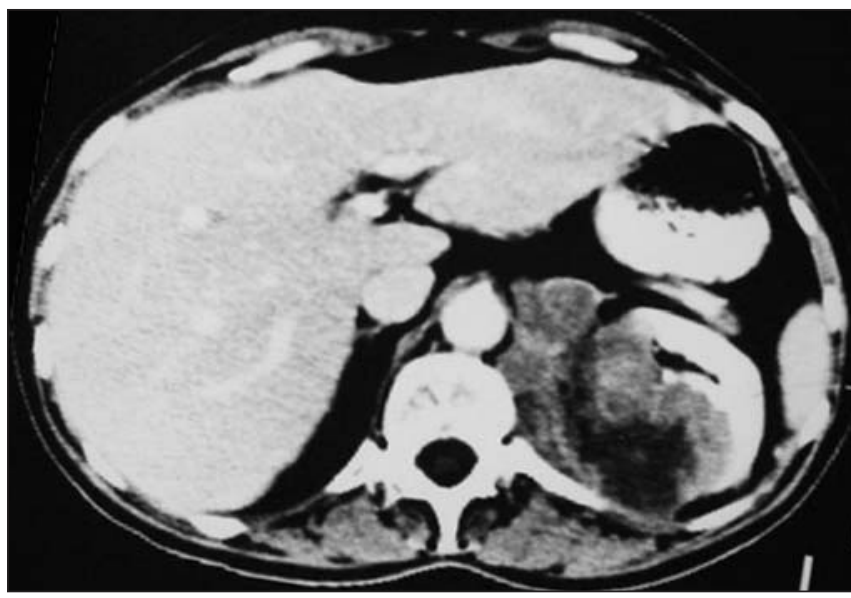

B

Figura 11. Linfoma retroperitoneal crescendo em direção ao espaço perirrenal e daí envolvendo mais agressivamente o parênquima renal. 
lateral e ocorre em cerca de $20 \%$ dos pacientes. O diagnóstico muitas vezes é difícil e se baseia no aumento difuso dos rins. Neste estádio a detecção pode ser extremamente difícil e injeção venosa de contraste é necessária para o diagnóstico. Alguns autores consideram que a forma difusa na verdade representa extenso envolvimento multifocal (Figura 12) por minúsculas massas $^{(5)}$. Quando as áreas de infiltração se tornam mais focais, é notada uma interface mal definida com o parênquima normal adjacente e os contornos são ligeiramente lobulados. Pode ocorrer comprometimento da função (Figura 13), mas em grande parte dos casos a função normal está mantida. Isto faz com que muitos casos sejam diagnosticados apenas após a quimioterapia, quando os rins voltaram ao tamanho normal e os contornos estão mais lisos. Muito raramente, uma grande massa pode infiltrar difusamente todo o rim e se apresentar como tumor não-funcionante.

\section{PADRÕES ATÍPICOS}

A grande maioria dos pacientes com linfoma renal tem padrões de acometimento e achados de imagem característicos. Raramente, alguns aspectos atípicos são encontrados: hemorragia espontânea, necrose, atenuação heterogênea, transformação cística e calcificações. Alguns destes achados podem ser seqüela de tratamento prévio do linfoma. Na maioria dos casos, o rim retorna ao normal após tratamento.

\section{CONCLUSÃO}

Linfoma renal primário é muito raro e sua existência é até questionada. Envolvimento secundário do rim por linfoma já é bem mais freqüente. Apenas metástases renais de neoplasias de pulmão e mama são mais frequientes.

Figura 12. Linfoma na forma infiltrativa $(\mathbf{A}, \mathbf{B})$. Os rins estão aumentados de tamanho, com contornos lobulados. Mesmo após meio de contraste venoso, as massas renais não são discerníveis. Após quimioterapia (C), os rins estão praticamente normais.

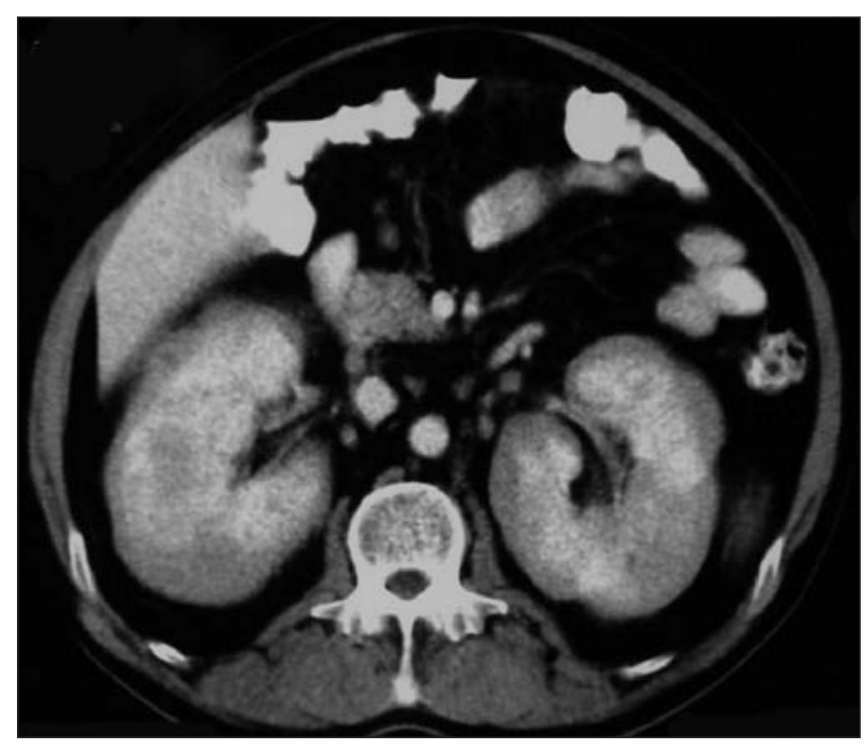

B

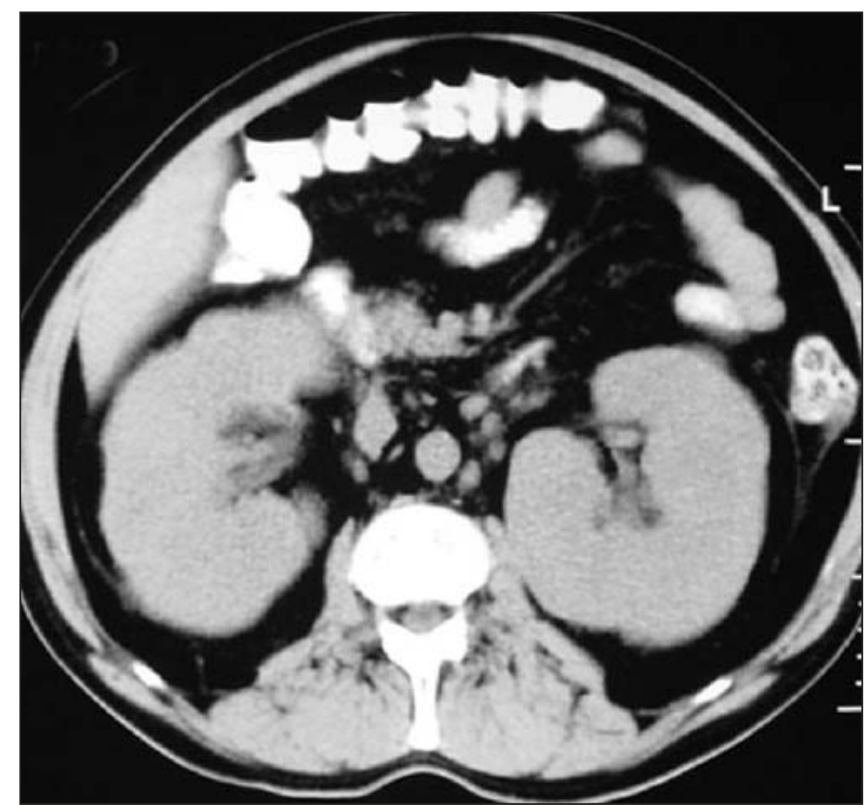

A

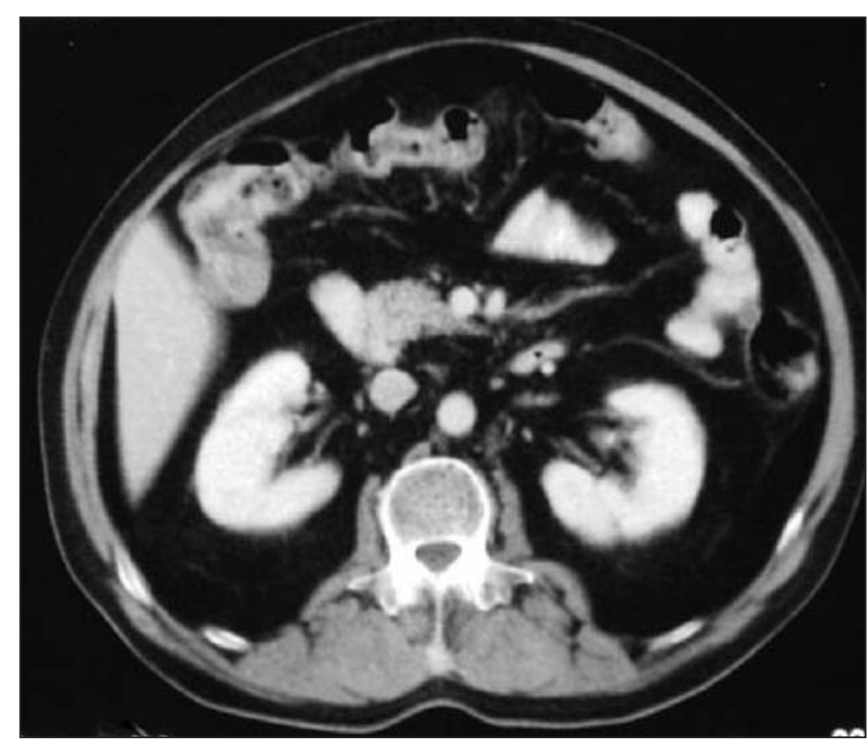

C 


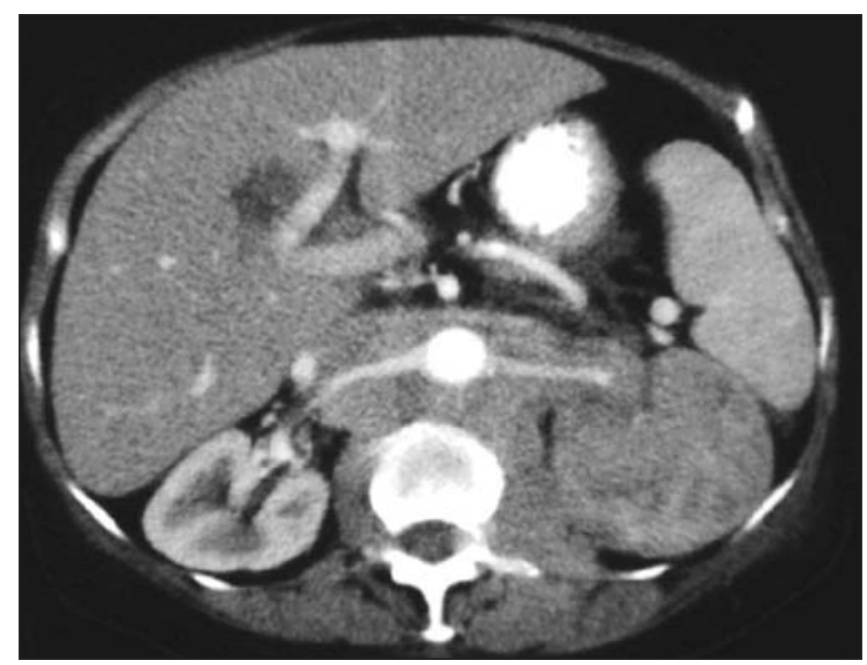

A

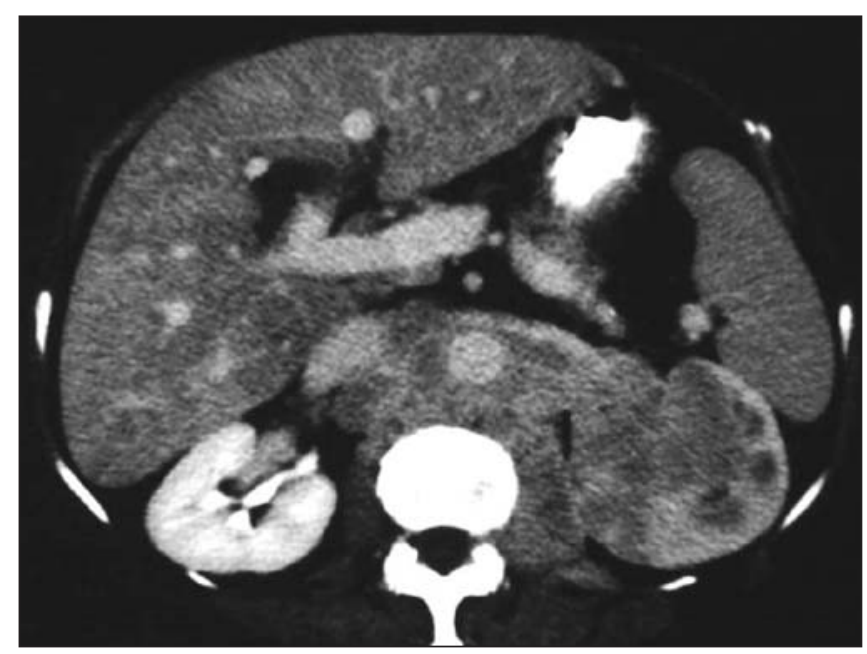

C

O linfoma renal é, em geral, clinicamente silencioso e manifesta-se tardiamente na doença. Os aspectos macroscópico e de imagem dependem do mecanismo de envolvimento renal (hematogênico ou extensão direta), do padrão de crescimento intra-renal (intersticial ou expansívo), do tamanho, número e distribuição das lesões, e do grau de extensão além do parênquima renal.

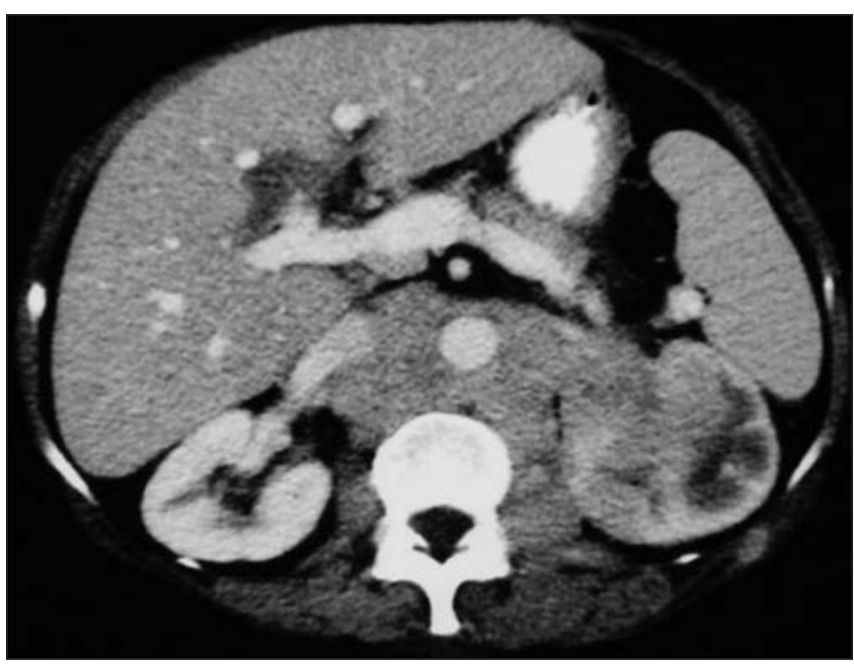

B

Figura 13. Linfoma na forma infiltrativa. Extensa lesão retroperitoneal, com envolvimento vascular e extensão para o parênquima renal. Não há imagem de massa discernível, e mesmo com extenso comprometimento do parênquima o aspecto reniforme é mantido.

\section{REFERÊNCIAS}

1. Dimopoulos MA, Moulopoulos LA, Costantinides C, Deliveliotis C, Pantazopoulos D, Dimopoulos C. Primary renal lymphoma: a clinical and radiological study. J Urol 1996;155:1865-7.

2. Richmond J, Sherman RS, Diamond HD, Craver LF. Renal lesions associated with malignant lymphomas. Am J Med 1962;32:184-207.

3. Davidson AJ, Hartman DS, Choyke PL, Wagner BJ. Radiology of the kidney and genitourinary tract. Philadelphia, PA: WB Saunders, 1999:249-55.

4. Urban BA, Fishman EK. Renal lymphoma: CT pat- terns with emphasis on helical CT. RadioGraphics 2000;20:197-212.

5. Hartman DS, David CJ Jr, Goldman SM, Friedman AC, Fritzsche P. Renal lymphoma: radiologic-pathologic correlation of 21 cases. Radiology 1982; 144:759-66.

6. Semelka RC, Kelekis NL, Burdeny DA, Mitchell DG, Brown JJ, Siegelman ES. Renal lymphoma: demonstration by MR imaging. AJR 1996;166: 823-7.

7. Cohan RH, Dunnick NR, Leder RA, Baker ME. Computed tomography of renal lymphoma. J Comput Assist Tomogr 1990;14:933-8. 